\title{
MRI Measurement of Normal Pituitary Size Using Volumetric Imaging in Scottish Patients
}

\author{
John Sinclair ${ }^{1}$, Avinash Kumar Kanodia ${ }^{2 *}$, Nicola Schembri², Thiru Sudarshan $^{2}$ and Prasad Guntur ${ }^{2}$ \\ ${ }^{1}$ Department of Cardiology, Ninewells Hospital, Dundee, UK
}

${ }^{2}$ Department of Radiology, Ninewells Hospital, Dundee, UK

Submission: March 05, 2017; Published: April 26, 2017

*Corresponding author: AK Kanodia, Department of Radiology, Ninewells Hospital, Dundee DD2 1SX, UK, Email: avinash.kanodia@nhs.net

\begin{abstract}
Pituitary size can vary between normal subjects depending upon age, sex and other conditions. It is important to know the range of normal size to enable radiologists to suggest what might be an abnormal pituitary gland. Previous studies into the size and shape of the normal pituitary gland have previously been performed in the 1980's during the dawn of the magnetic resonance imaging (MRI) with old technology, but not on any 3-dimensional sequence using isometric voxels. This study aims to produce accurate data for the dimensions of the normal pituitary gland in 101 patients and is first study using 3D FLAIR sequence. Our results show a mean pituitary gland height for males of $5.52 \pm 0.73 \mathrm{~mm}$ and $5.66 \pm 0.96$ for females which is consistent with previous similar studies performed internationally. Our data also postulates the relationship between the different dimensions of the pituitary gland in relation to the age of the patient with regards to the height, width and depth of the gland. We have also highlighted the need for a standard for accurate measurement of the pituitary gland size and further studies into the volumetric changes in relation to age.
\end{abstract}

\section{Introduction}

The pituitary gland is located in pituitary fossa within sphenoid bone. This region has significant variations between normal individuals, including sphenoid sinus, size of sella including depth and size and shape of pituitary gland [1,2]. While in the majority of patients, it is subjectively possible to differentiate normal from abnormal, there is a significant grey area where a reporting radiologist faces dilemma whether the pituitary is within normal limits or not, often resulting in unnecessary further investigations. It is therefore important to define "normal" more accurately to reduce the "grey" zone and prevent unnecessary clinical concern and investigations. Despite its importance, only a few studies have been performed to analyse the size, shape and structure of the normal pituitary gland. The majority of the known published data is in excess of 20 years ago and these studies were specific to certain populations such as paediatrics [3-6]. This report aims to produce normal data for the size, in particular the height, of the normal pituitary gland using latest 3D magnetic resonance imaging (MRI) and will also comment on the shape and stalk position. Such data is important to validate and upgrade the older scant data. While the older studies were performed Japan or United States of America, and more recently from Africa there has been scant data from Europe. Unlike previous studies, the aim of this study is not to statistically compare the difference in pituitary gland sizes between different populations, this is purely a collection of population data using up to date technology.
Morphological changes to the pituitary gland, analysed using imaging, have been documented within normal subjects with emphasis on the change in pituitary gland height and shape during childhood, adolescence, pregnancy and post-partum [3-6]. Earlier studies were performed using computerised tomography (CT) imaging as opposed to MRI. Weiner et al. [7] demonstrated that with regards to the pituitary gland, measurements were essentially equivalent using either CT or MR imaging with the technologies at the time [7]. However with regards to modern day technology the advancements in the imaging capabilities make MRI the modality of choice for imaging the pituitary gland1.

Previous studies have shown a clear trend with regards to the morphology of the pituitary gland in relation to the age and sex of the subjects [3-6]. Kato et al. [8] studied 300 individuals using a 1.5 Testla (1.5T) MRI unit in Chiba Japan and noted the mean height of the pituitary gland to be $5.1 \pm 2.0 \mathrm{~mm}$, with a nonsignificant difference breakdown of $4.9 \pm 1.9 \mathrm{~mm}$ (mean \pm SD) for males and $5.2 \pm 2.0 \mathrm{~mm}$ for females8. They also demonstrated that the height was significantly higher in the 20-49 age groups than in the older age groups [8]. Very similar results have been observed also using a 1.5T MRI unit and T1-weighted MR images by Tsunoda et al. [4] in Tokyo Japan with 1020 subjects. They noted the total mean pituitary height as being $5.1 \pm 1.1 \mathrm{~mm}$ (mean \pm SD) and a breakdown of $4.93 \pm 1.05 \mathrm{~mm}$ for males and $5.35 \pm 1.12 \mathrm{~mm}$ for females. Peyster et al. [9] developed the hypothesis that normal pituitary gland enlarges due to physiological hyperplasia 


\section{Current Trends in Clinical \& Medical Imaging}

during puberty and evidence was submitted by Estler et al. [10] which further supported this hypothesis $[9,10]$.

\section{Materials and Methods}

This study was approved by the University of Dundee's Department of Public Health. This was a retrospective analysis using 3D fluid-attenuated inversion recovery (3D FLAIR) sequences from a Siemens 1.5T MRI scanner unit located in Ninewells Hospital Dundee, Scotland. Sequence parameters include TR-5000ms, TE-333ms, FoV- 260(read), FoV (phase)-87.5, slice thickeness-1mm, base resolution-256x256, phase resolution-97, slice resolution-80.

All of the head MR images were analysed using Picture Archive and Communication System (PACS) on the same reporting station in Ninewells Hopsital Dundee, Scotland. The data was collected retrospectively from 114 patients who were over the age of 16 .
Patients were selected in sequential chronological order who had had a MRI head scan with 3D FLAIR sequences over a one month period.

The main exclusion criteria are:

a) Patients who were being assessed for a possible pituitary abnormality;

b) There was a pituitary abnormality of any sort reported in the scan report;

c) There was a possible structural abnormality of the pituitary observed during analysis. A total of $5(4.4 \%)$ patients were excluded due to an empty sella and $8(7 \%)$ were excluded due to an obvious pituitary enlargement of some description and suspicious of potential pituitary adenoma.

\section{Measurements}

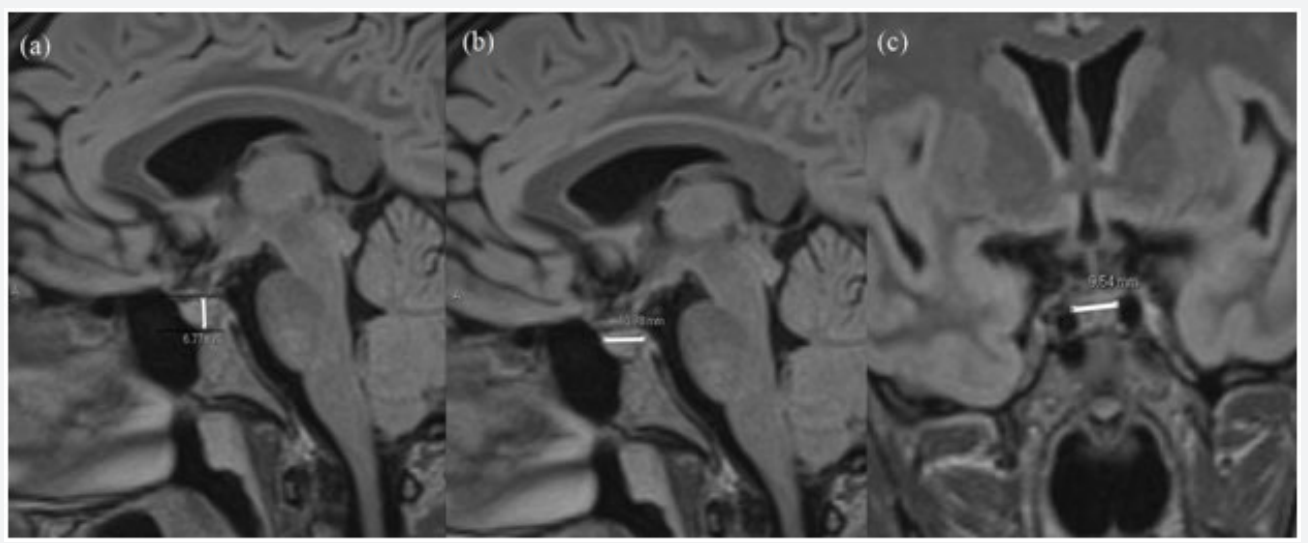

Figure 1: 3D FLAIR sequence; sagittal $(a, b)$ and coronal reconstructions (c). (a) shows measurement technique used for measuring height using two parallel lines (black) above and below pituitary gland, height being the distance between them. Similar technique has been used in $(b, c)$ for other dimensions.

The 3D FLAIR sequences were analysed using multiplanar reconstruction (MPR) which allowed the images to be observed in the coronal, sagittal and axial planes at the same time. Standard measurement technique was used. Using PACS's measurements feature, guide lines were drawn superior and inferior to the pituitary gland in the midsagittal plane and the distance between these lines measured the height of the gland (Figure 1A). Also in the midsagittal plane, similar method was used to measure the distance between anterior and posterior margins, referred to as depth of the gland (Figure 1B). In the midcoronal plane the same technique was used to measure the width of the pituitary gland (Figure 1C). The shape of the superior aspect of the gland was also noted whether it was predominantly convex, flat or concave shaped in the coronal plane. Also the pituitary stalk position was noted as to whether the stalk was central or deviated to one side.

\section{Results}

Table 1: Table showing the mean data for all Males and Females \pm standard deviation. The percentage of concave pituitary glands as opposed to convex glands and the position of the pituitary stalk were also noted.

\begin{tabular}{|c|c|c|c|c|c|}
\hline & $\begin{array}{l}\text { Height }(\mathrm{mm}) \\
(\text { mean } \pm S D)\end{array}$ & $\begin{array}{l}\text { Width }(\mathrm{mm}) \\
(\text { mean } \pm S D)\end{array}$ & $\begin{array}{c}\text { Depth }(\mathrm{mm}) \\
(\text { mean } \pm \text { SD) }\end{array}$ & $\%$ Concave & $\begin{array}{l}\text { Number of Non- } \\
\text { Centred Stalks }\end{array}$ \\
\hline Male $(n=37)$ & $5.52 \pm 0.73$ & $11.57 \pm 1.42$ & $11.18 \pm 1.1$ & $75.70 \%$ & $1^{*}$ \\
\hline Female $(n=64)$ & $5.66 \pm 0.96$ & $11.91 \pm 1.61$ & $11.09 \pm 1.01$ & $62.50 \%$ & $2^{*}$ \\
\hline Collective ( $n=101)$ & $5.61 \pm 0.87$ & $11.78 \pm 1.54$ & $11.12 \pm 1.04$ & $67.30 \%$ & $3^{*}$ \\
\hline
\end{tabular}

*right sided stalk deviation 


\section{Current Trends in Clinical \& Medical Imaging}

Table 2: Table represents the data collected split into the 6 age categories. The percentage of concave pituitary glands as opposed to convex glands and the position of the pituitary stalk were also noted.

\begin{tabular}{|c|c|c|c|c|c|}
\hline & Height (mean \pm SD) & Width (mean \pm SD) & Depth (mean $\pm S D)$ & $\%$ Concave & $\begin{array}{l}\text { Number pf Non- } \\
\text { Centred Stalks }\end{array}$ \\
\hline $16-25(n=13)$ & $6.19 \pm 1.22$ & $11.63 \pm 1.31$ & $10.56 \pm 0.93$ & $53.80 \%$ & 0 \\
\hline $35-45(n=12)$ & $5.88 \pm 1.11$ & $11.65 \pm 1.11$ & $11.19 \pm 0.83$ & $75 \%$ & $1^{*}$ \\
\hline $45-55(n=21)$ & $5.53 \pm 0.75$ & $12.20 \pm 1.58$ & $10.88 \pm 0.81$ & $57 \%$ & 0 \\
\hline$>65(n=23)$ & $5.40 \pm 0.68$ & $11.42 \pm 1.4$ & $11.57 \pm 1.24$ & $60.90 \%$ & 0 \\
\hline
\end{tabular}

*right sided stalk deviation

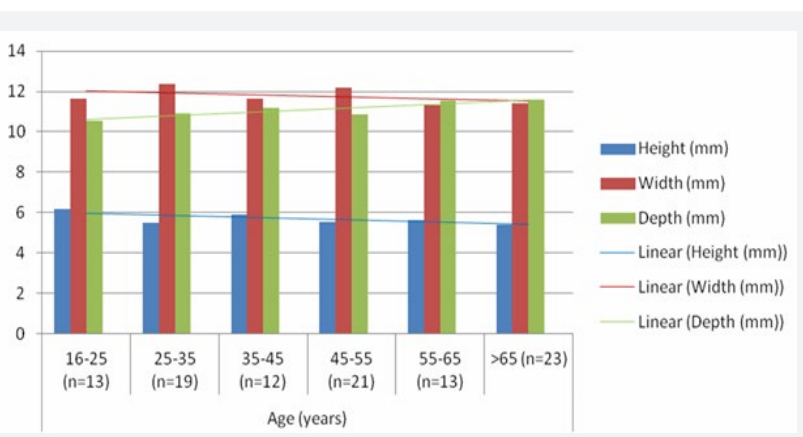

Figure 2: Bar graph illustrates a visual difference in the different dimensions of the pituitary gland with respect with height, width and depth of the gland. Trend lines have also been added to this bar graph to further illustrate the trends in the different dimensions through the age groups.

A table was produced differentiating the patients by sex and for all of the patients collectively (Table 1 ). The patients were also grouped into 6 different age categories 16-25, 25-35, 35$45,45-55,55-65$ and $>65$ (Table $2 \&$ Figure 2). Mean value for each category was calculated as was the Standard Deviation from the Mean. All of the data collected was correlated into tables for different groups of patients. Although, as previously mentioned, the purpose of this study was not to compare the pituitary gland sizes of different categories of patients, a graph illustrating the linear decrease in average pituitary gland height with increasing age groups was also created (Figure 2). No male patients had a pituitary height less than $4.36 \mathrm{~mm}$ or greater than $7.10 \mathrm{~mm}$; a width less than $7.75 \mathrm{~mm}$ or greater than $14.42 \mathrm{~mm}$ and a depth less than $8.55 \mathrm{~mm}$ or greater than $13.50 \mathrm{~mm}$. Whereas no female patients had a pituitary height less than $4.02 \mathrm{~mm}$ or greater than $9.10 \mathrm{~mm}$; a width less than $8.87 \mathrm{~mm}$ or greater than $16.19 \mathrm{~mm}$ and a depth less than $9.35 \mathrm{~mm}$ or greater than $12.95 \mathrm{~mm}$.

The shape of the superior aspect of the pituitary gland was noted and is represented as a percentage of concave shaped glands. The position of the pituitary gland stalk was also noted as to whether or not it was central.

\section{Discussion}

MRI brain is a commonly performed examination and all radiologists carefully observe pituitary gland to determine if it is normal. It is therefore important to determine what constitutes "normal" and when to raise a concern for specialist referral for further investigations. With regards to the purpose of this project, this study was successful in producing concise data for 'normal' pituitary dimensions from a 'healthy' population using latest MRI techniques, meant to be more accurate and first study of its kind. Previously, there have been population studies to gain insight into the size of the pituitary gland done internationally a significant time ago in the 1980's and 1990's $[3-7,10]$. This study was primarily performed due to the lack of up to date data using currently used techniques and technology, in order to improve or validate the known data. The results from this study give a mean pituitary gland height of $5.66 \pm 0.96 \mathrm{~mm}$ for females and $5.52 \pm 0.73$ for males. Wolpert et al. [13] studied the size, shape and appearance of the normal female pituitary gland and in particular looked into its morphology in connection with hormonal function $[8,13]$. Their results are remarkably similar with the data produced in this study with a mean pituitary gland height of $5.7 \mathrm{~mm}$ from 107 women aged 18-65 measured using contrast-enhanced CT.

One key issue with all scientific research is that of reproducible results and this study is no different. With regards to accurate measurements of the pituitary gland, the slightest error may constitute to a gross over or under calculation of gland dimensions. The difficulty in the accuracy and consistency of measurement techniques was better understood when measuring pituitary glands where the superior aspect was concave in shape. Alternate techniques led to a grossly different measurement of pituitary gland height with one difference of the same gland noted to be greater than $3 \mathrm{~mm}$. Therefore for the purpose of scientific consistency only one technique was used to measure the gland dimensions in this study as mentioned in the materials and methods section. This further highlights the possible need for a radiological standard for the measurement of pituitary gland size.

An unavoidable limitation to this study was the limitation that all patients must be over 16 years old, which was a condition of the University of Dundee Caldicott approval for this study. Had full access to the patients notes been available then factors such as ethnicity and lactation could also be addressed and accounted for. To date no studies have been performed which highlight the differences in the size of the pituitary gland within closed ethnic groups. This study also did not take into account the ethnic background of the patients. Pregnancy status is one other 


\section{Current Trends in Clinical \& Medical Imaging}

major factor which may have a significant impact on the size of pituitary gland; there have been many studies which illustrate quite clearly that the pituitary gland increases in size during pregnancy [6]. We only rarely perform MRI in pregnant patients; none of the patients included in this study had known pregnancy. However, it was not known how many patients were lactating.

The exclusion criteria used in this study are for the most part self-explanatory, with any reports mentioning the pituitary being excluded. As previously mentioned 5 patients were excluded due to an apparent empty sella, this occurs when the sella has partially or completely been filled with cerebrospinal fluid [11]. We took an upper limit of $4 \mathrm{~mm}$ to define partial empty sella. This finding equates to approximately $4.4 \%$ incidence within the 114 patients analysed and is consistent with previous studies stating that the empty sella is found in approximately $5 \%$ of patients $[4,11]$. Also a common incidental finding within the population is that of a pituitary adenoma with studies estimating that $10 \%$ of the adult population have an asymptomatic pituitary adenoma [12]. The incidence of a suspected pituitary adenoma within this study equates to approximately $7 \%$, this can be either due to the small population size or an underestimation of the number of pituitary adenomas within this population, since none of these studies were meant to investigate pituitary gland.

Although many of the previous studies used a retrospective analysis of scans for medical reasons unrelated to the pituitary gland, as did this study, given the primary role of the pituitary gland within the body it could be suggested that many of the measurements were askew due to systemic disease. Also as one of the key measurements of the pituitary gland is the shape of the superior aspect it is easy to envisage how a variation in the shape in the midsagittal plane may cause a gross underestimation of the pituitary gland height.

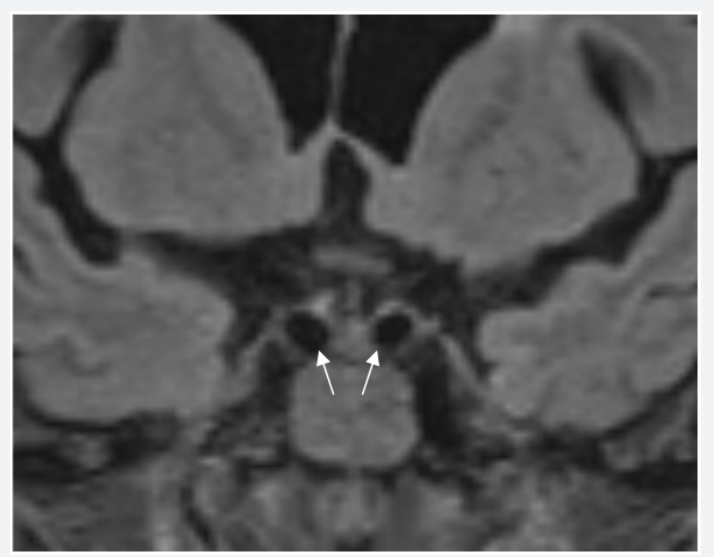

Figure3:3D FLAIR coronal reconstruction shows tortuous internal carotid arteries (white arrows) distorting pituitary, potentially reducing its width in old patients.

Although the main key quoted figures when discussing pituitary gland size is the height of the gland, this study also attempted to gain further insight into the width and depth of the gland as well. It is very questionable as to whether such dimensions of the pituitary gland are clinically relevant.
However although the data has not been statistically analysed a visual trend can be seen in the graph of Figure 3 in the results section. This trend suggests that with increasing age the height of the pituitary gland decreases and the depth of the pituitary gland increases. It may also be noted, although it is quite subtle, that there is an increased width to depth size ratio in the younger age groups $(<55)$ and that in the older age groups $(>55)$ it is the depth which is the greater size on average. It is possible that with increasing age, since the internal carotid arteries in cavernous regions become more tortuous, these distort the pituitary gland from side to side (Figure 3) and result in reduced width and therefore increased depth. Further volumetric studies and analysis would be needed to ascertain whether these changes equate to a change in pituitary gland volume with age. It can be reasonably argued why volumetric studies were not performed, despite volumetric sequence performed and volumetric data potentially available. It was a conscious decision since most radiologists still measure $2 \mathrm{D}$ dimensions, particularly height increasingly on $3 \mathrm{D}$ sequences, so for practical usefulness in day to day practice, better definition of measurements was thought to be a more useful outcome. Based on the data obtained (mean+2SD), we recommend that a height of $7.6 \mathrm{~mm}$ be taken as upper limit of normal for females and $7 \mathrm{~mm}$ for males (above 16 years and in absence of pregnancy). However, this would need to be further validated by larger similar studies.

A future larger study with greater emphasis on patient categorisations such as ethnicity, pregnancy and lactation status would hopefully provide additional evidence to support the results gained from these 101 patients. Also volumetric studies of the pituitary gland with age may yield interesting results in connection with our 2D dimensional results for the pituitary gland size.

\section{Conclusion}

This study provides up-to-date data regarding the normal dimensions of the human pituitary gland, using a commonly performed 3D volumetric sequence, providing better accuracy. The results give normal data regarding the pituitary gland with regards to sex and age of different patients. The data collected may be used for future larger studies regarding the normal pituitary gland. Using such larger studies a standard value for the size of the pituitary gland may be produced with more confidence.

\section{References}

1. Chaudhary V, Bano S (2011) Imaging of the pituitary: Recent advances. Indian J Endocrinol Metab 15(Suppl3): S216-S223.

2. Elster AD (1993) Imaging of the sella: anatomy and pathology. Semin Ultrasound CT MR 14(3): 182-194.

3. Lurie SN, Doraiswamy PM, Husain MM, Boyko OB, Ellinwood EH, et al. (1990) In vivo assessment of pituitary gland volume with magnetic resonance imaging: the effect of age. J Clin Endocrinol Metab 71: 505508.

4. Tsunoda O, Okuda O, Sato K (1997) MR Height of the Pituitary Gland as a Function of Age and Sex: Especially Physiological Hypertrophy in Adolescence and in Climacterium. Am J Neuroradiol 18(3): 551-554. 


\section{Current Trends in Clinical \& Medical Imaging}

5. Tien RD, Kucharczyk J, Bessette J, Middleton M (1992) MR imaging of the pituitary gland in infants and children: changes in size, shape, and MR signal with growth and development. Am J Roentgenology 158 1151-1154.

6. Elster AD, Sanders TG,Vines FS, Chen MY (1990) Size and shape of the pituitary gland during pregnancy and post partum: measurement with MR imaging. Radiol 181(2): 531-555.

7. Wiener SN, Rzeszotarski MS, Droege RT, Pearlstein AE, Shafron M (1985) Measurement of pituitary gland height with MR imaging. Am J Neuroradiol 6(5): 717-722.

8. Kunihiko Kato MD, Naokatsu Saeki MD, Akira Yamaura MD (2002) Morphological changes on MR imaging of the normal pituitary gland related to age and sex: main emphasis on pubescent females. J Clin Neurosci 9(1): 53-56

9. Peyster RG, Hoover ED, Viscarello RR, Moshang T, Haskin ME (1983) CT appearance of the adolescent and preadolescent pituitary gland. Am J Neuroradiol 4(3): 411- 414.
10. Elster AD, Chen MY, Williams DW, Key LL (1990) Pituitary gland: MR imaging of physiologic hypertrophy in adolescence. Radiol 174(3 pt 1): 681-685.

11. Bjerre P (1990) The empty sella. Acta Neurol Scand Suppl 82: 1-25

12. Hall WA, Luciano MG, Doppman JL, Patronas N, Oldfield EH (1994) Pituitary Magnetic Resonance Imaging in Normal Human Volunteers: Occult Adenomas in the General Population. Ann Intern Med 120(10): 817-820.

13. Wolpert SM, Molitch ME, Goldman JA, Wood JB (1984) Size, Shape, and Appearance of the Normal Female Pituitary Gland. Am J Neuroradiol 143(2): 377-381.

14. Ibinaiye PO, Olarinoye-Akorede S, Kajogbola O, Bakari AG (2015) Magnetic Resonance Imaging Determination of Normal Pituitary Gland Dimensions in Zaria, Northwest Nigerian Population. Journal of Clinical Imaging Science 5: 29.

\section{Your next submission with Juniper Publishers} will reach you the below assets

- Quality Editorial service

- Swift Peer Review

- Reprints availability

- E-prints Service

- Manuscript Podcast for convenient understanding

- Global attainment for your research

- Manuscript accessibility in different formats

( Pdf, E-pub, Full Text, Audio)

- Unceasing customer service

Track the below URL for one-step submission https://juniperpublishers.com/online-submission.php 